\title{
CIRCULATION IN THE HAGFISH, MYXINE GLUTINOSA L.
}

\author{
KJELL JOHANSEN 1
}

\author{
University of Oslo, Institute for Experimental Medical Research, Oslo, Norway
}

Knowledge of the circulation in fishes and in cyclostomes in particular is very restricted and inadequate for comparison with the data available on circulation in higher vertebrates. Myxine glutinosa L., which is the species used for this study, belongs to the class Cyclostomata and the family Myxinidae. These animals represent phylogenetically the most primitive of the existing vertebrates and thus occupy a critical position in comparative interpretations. This study seems to be the first one quantitatively undertaking problems related to the dynamics of circulation in myxinoids.

Fishes are considered to have one circulatory pump, the systemic heart, for the propulsion of blood through both the gill and the general body capillaries. Additional hindrance to circulation exists in the special porta and in some species the kidney capillary systems. The circulatory system in myxinoids is provided with several specialized structures. Apart from the systemic heart in Myxine glutinosa there are three accessory hearts on the venous side of the circulation. These are the portal heart, the cardinal hearts and the caudal hearts. The portal heart was first described by A. Retzius in 1822 . This heart resembles the atrium of the systemic heart and differs from the other accessory hearts by having a relatively large lumen and striated muscle fibers with a consequent greater pumping capacity. The three orifices of the portal heart, the right anterior cardinal vein, the portal vein and the main portal vein have valves. The two first vessels represent the afferent channels and the latter the efferent channel of the portal heart. The cardinal hearts (Cole, 1926) exist as enlarged anterior extremities of the deep anterior cardinal veins. The caudal hearts (Retzius, 1822) are paired expansions on the caudal veins. The efferent vessels of the caudal hearts unite anteriorly to form the median caudal vein. At this point valves are situated which cause unidirection of the venous blood stream. The present study draws particular attention to the role of the gills in the myxinoid circulation and results are presented which demonstrate an active role of the gills for the propulsion of the arterialized blood.

The six bilateral pairs of gills are located in the region cephalad to the heart and caudal to the big tongue muscle. The gills are connected to the oesophagus through the inner gill ducts which constitute the afferent channels for the respiratory water. After passing through the lense or pouch-like gills, the water flows out through the efferent gill ducts which unite on each side and leave the animal through the two branchial openings. A cross-section through a gill will show tissue that projects inwards from the periphery of the gill as a number of radial

${ }^{1}$ Present address: Dept. of Physiology and Biophysics, School of Medicine, University of Washington, Seattle 5, Washington. 
plates, each one clothed by the walls of two adjacent evaginations differentiated from the epithelial lining of the gill. What may be called gill lamellae are represented by the contiguous walls of two adjacent evaginations plus the intervening vascular tissue.

The afferent gill arteries come from the ventral aorta and form a circular vessel around each efferent gill duct (Fig. 1). From this circle, several radial

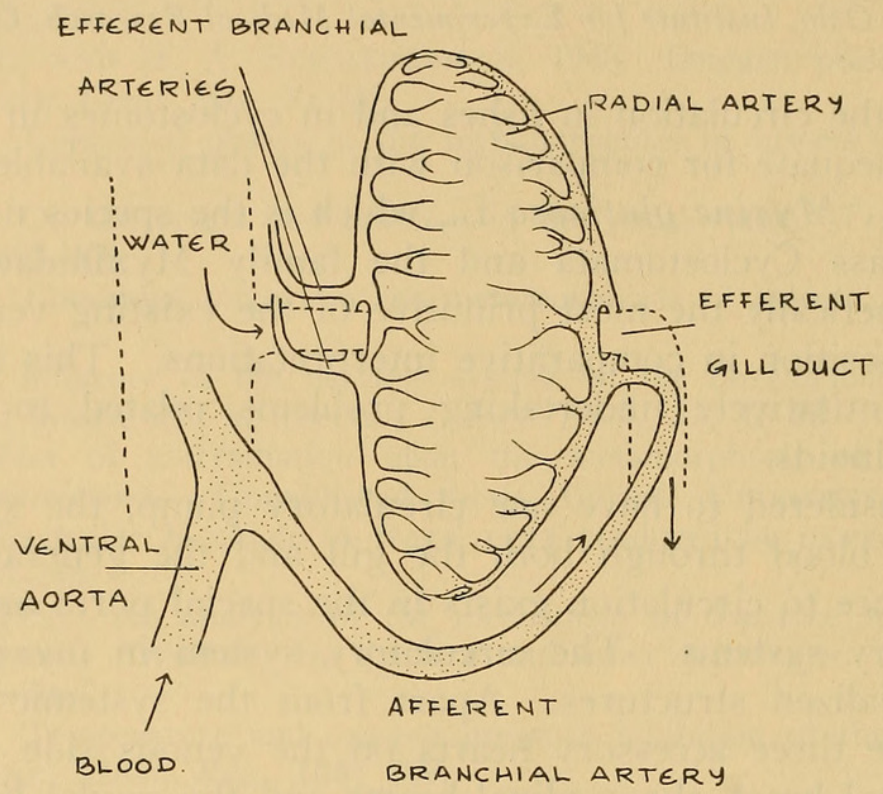

FIGURE 1. (A) Schematic dráwing of the vascular arrangement in a gill-body of Myxine glutinosa.



FIGURE 1. (B) Detail showing the topography of a circular vessel and the muscular elements in the gill ducts and gill body.

arteries arise which give off a number of vessels at right angles. These vessels travel in the core of the gill lamellae and join into another series of radial arteries which open into a second circular vessel around the afferent gill duct. From this circular vessel two efferent branchial arteries arise which communicate with the left and right carotid arteries.

A brief histological examination of the gills shows a respiratory epithelium in 
$\mathrm{mm} \mathrm{Hg}$



Figure 2. Blood pressure record from the dorsal aorta in Myxine glutinosa. Time marks, 4 seconds.

contact with a thin sheet of connective tissue in which the blood vessels are running. Next there are two muscular layers, an external, circular or concentric (constrictor branchialis externus) and an internal radial (constrictor branchialis internus), the axis being the gill ducts. All muscle fibers are distinctly striated. A somewhat similar structure to that in the gill is also present in the gill ducts. The musculature, however, consists only of ring muscles (Fig. 1B). It is of special importance that the gill muscles are not a direct continuation of the gill duct muscles, but that the circular vessels on both sides of a gill body are lying between the ring muscles in the duct and the ring muscles in the gill itself (Fig. 1B). The structure of the myxinoid gills is distinctly different from all other fish-type craniotes, even including petromyzonts.

\section{Materials and Methods}

The specimens used for this study were trapped near the Dröbak Biological Station in the Oslofiord in Norway. The animals were kept in aquaria supplied with running sea water of $4-7^{\circ} \mathrm{C}$. The largest available specimens were used for the experiments. Their length ranged from $25-40 \mathrm{~cm}$. The unanesthetized animal was fastened to a dissection board which was placed in a lucite box filled with oxygenated sea water of $4-7^{\circ} \mathrm{C}$. Two incisions were made; the first, in the region 5-8 cm. cephalad to the cloacal opening, exposed the dorsal aorta and the caudal vein. A polyethylene catheter (P.E. 50) was introduced into the dorsal

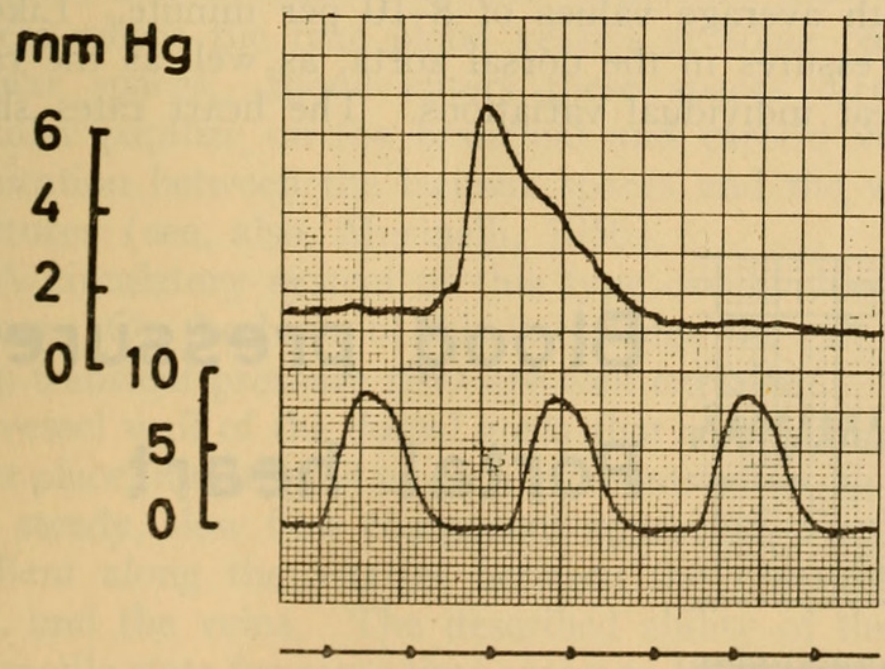

\section{Blood pressure Dorsal aorta}

\section{Ventricle}

FigURE 3. Simultaneous blood pressure records from the dorsal aorta (upper curve) and the heart ventricle. Time marks, 1 second. 
$\mathrm{mm} \mathrm{Hg}$

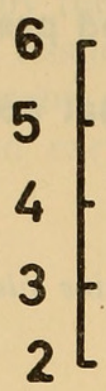



Blood pressure

\section{Dorsal aorta}

Figure 4. Blood pressure record from the dorsal aorta showing sustained gill contraction. Time marks, 2 seconds.

aorta and connected with a Statham or Sanborn pressure transducer. Another incision in the branchial region exposed the systemic and portal hearts. Sometimes the gills themselves were dissected free in order to follow their movements closely. The pressures in the ventricle of the systemic heart and in the portal heart were recorded via cannulas (gauge 26) to the pressure transducers. Care was taken not to alter the horizontal position of the animals during the experiments and temperature changes in the lucite box were avoided. All recordings were made on a Sanborn 4-channel recorder.

\section{Results}

The systemic heart showed a frequency different from that of the portal heart. Both the systemic and portal hearts increased their frequency as a result of increased venous return brought about by digital manipulation of the great veins.

The blood pressure recorded in the dorsal aorta showed a pattern like that demonstrated in Figure 2. The smaller oscillations are transmissions of the systemic heart beat through the gill capillaries. The larger paired pressure pulses were the result of active contractions of the gill musculature. These contractions most often came in pairs separated by variable times. The frequency of the gill contractions varied greatly, with average values of 8-10 per minute. Likewise, the absolute values of blood pressures in the dorsal aorta, as well as the rate of the systemic heart, showed great individual variations. The heart rates showed

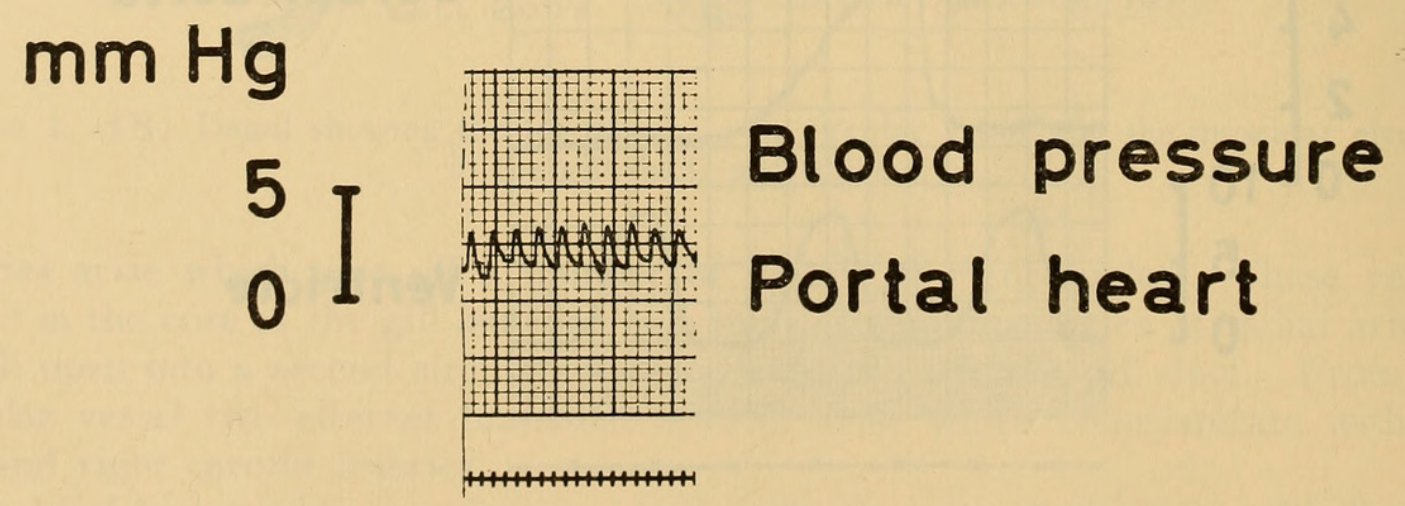

FIGURE 5. Blood pressure record from the portal heart. Time marks, 1 second. 
variations between $30-40$ beats per minute. The mean blood pressure in the dorsal aorta most often showed values around $5 \mathrm{~mm}$. Hg, varying between $3-8 \mathrm{~mm}$. $\mathrm{Hg}$. The pulse pressures resulting from the systemic heart beat showed values of around $2 \mathrm{~mm}$. $\mathrm{Hg}$ or $25 \mathrm{~mm}$. of water. All these pressure values were recorded in the caudal part of the animal in the dorsal aorta. Figure 3 demonstrates pressures in the heart ventricle and dorsal aorta recorded simultaneously. The blood-pressure drop across the gill capillaries calculated from the average pressures in the heart ventricle and dorsal aorta amounted to $4.0 \mathrm{~mm}$. Hg. The lower tracing in Figure 3 shows that intra-ventricular systolic pressure is around $8.5 \mathrm{~mm}$. $\mathrm{Hg}$ while the diastolic pressure is zero. During other experiments the same values varied between $15 \mathrm{~mm}$. $\mathrm{Hg}$ and zero. Figure 4 shows another feature of the gill contractions, namely the ability to sustain the contractile state for some seconds. The pressure in the portal heart (Fig. 5) was consistently between 3-6 mm. Hg.

\section{Discussion}

The circulation in Myxine glutinosa as demonstrated in this study differs markedly from circulation in all other vertebrates studied. Most surprising is the active role of the respiratory organs for the propulsion of blood. The unique morphology of the gills in Myxine, however, with the striated musculature and special vascular architecture might give reasons for anticipating an active participation of the gills in the circulation of blood. In fact, this is what M. Hofbauer (1937) suggests in her excellent description of the histology of the gills in Myxine glutinosa.

It is apparent from Figures 2 and 3 that the pressure wave resulting from a gill contraction has a very steep diastolic gradient. This means that the peripheral resistance is low. In attempting to elucidate the physiological importance of the gill contractions, one has to bring a disputed problem into consideration. This is the problem of lacunar circulation in vertebrates, first described by Rathke in 1825 . Cole (1926) pointed out that some of the lacunar spaces (blood sinuses) in Myxine contain red blood cells and he called them "red lymphatics." These cannot be considered true lymphatics but must be considered a part of the blood vascular system. The circulatory system of Myxine must thus be considered a semi-closed system where the true blood vessels at some particular sites are interrupted by lacunar spaces. Blood enters these spaces directly from the arteries through vascular papillae on the branchial and carotid vessels among others. The communication between the lacunar spaces and the veins are established with valved apertures (see, also, Marinelli, 1956).

A circulatory system of this type can evidently not work as a high pressure system. On the basis of this knowledge the gill contractions with the consequent steep transient pressure rises are well explained. Thus it can be observed through the vessel wall of the dorsal aorta that a steady, slow forward movement of blood takes place, interrupted at each gill contraction by a massive forward displacement. The steady, slow flow component apparently results from the permanent pressure gradient along the arteries between the pressure head from the systemic heart beat, and the veins. The described ability of the gills in Myxine to sustain the contractile state for some time seems to be of physiological importance to the animal by increasing the volume of blood displaced during a gill contraction. A con- 
tinuous, repeated blood transport of this type obviously necessitates the mentioned properly sited valves and accessory "hearts" on the venous side of the circulation.

The events in the gill pouch during contraction of the gill musculature are probably as follows: The two circular vessels on the afferent and efferent branchial arteries, at the entrance and exit of each gill, will each be pressed together when the striated musculature in the gills and gill ducts contracts. By this act the blood already arterialized will be forced out in the arterial trunks through the efferent branchial arteries, thereby causing the relatively high transient pressure rise throughout the arterial system. On the afferent or venous side of the gill the inflow of venous blood will stop during gill contraction. At the same time the water in the gill pouch has been pressed out, which means that the gill when contracted is in a state where the respiratory function is temporarily stopped. In other words the gills at this time are solely engaged in the circulation of blood and water. Upon relaxation of the gill muscles the inflow of water and venous blood again takes place and the gills resume their respiratory function.

Considerable interest relates to the events in the ventral aorta during a gill contraction. Recording of the pressure in this vessel without interfering with the normal circulation is extremely difficult and has not yet been successful. It may, however, be suggested that a simultaneous contraction of the gills and the systemic heart creates a pressure in the ventral aorta which surpasses a threshold necessary to fill the lacunar spaces through the vascular papillae on the afferent branchial vessels. It may well be reasoned that the outflow of blood through these papillae and into the lacunar spaces has a pressure threshold only brought about by a high pressure in the ventral aorta resulting from a simultaneous contraction of the gills and the systemic heart.

A comparison of the absolute values of pressure in the vessels and heart of Myxine with those reported earlier on selachians and teleosts are probably of limited value, considering that lacunar circulation is not present in the latter. The pressure drop across the gills, although these too differ markedly in their anatomy from gills in selachians and teleosts, is likely of some interest. Thus, Schoenlein and Willem (1894) working with selachians reported a pressure drop in per cent of values proximal to the gills of from 35 to $65 \%$. They worked with Torpedo sp. and Scyliorynchus catabus. Lyon (1926), working with Carcharias sp., reported around 25\% pressure drop, while J. Mott (1951) recorded 40 to $50 \%$ pressure drop in the common eel, Anguilla anguilla. The present study gave values of around $50 \%$ pressure loss across the gills measuring pressures in the ventral aorta and heart ventricle. During these recordings the catheter in the dorsal aorta was pushed in cephalad direction to avoid the pressure drop along the dorsal aorta itself. The size of the catheter, however, did not obstruct the circulation in the posterior direction in this vessel.

Another feature of probable physiological importance is explicitly demonstrated in the architecture of the myxinoid gill (Fig. 1). This has to do with the principle of counter currents, recently frequently stressed as being of great importance for efficient exchange of materials and energy as well as for maintenance of concentration gradients in biological systems (Scholander, 1958).

In conclusion it may be stated that the circulatory system in myxinoids, as judged from this study, shows a very decentralized mode of functioning. In other 
words the components actively taking part in the circulation of blood are distributed throughout the circulatory pattern. Hence the situation differs greatly from the circulation in other vertebrates where the systemic heart is considered the predominant site of the blood-moving power.

\section{SUMMARY}

1. Electromanometers have been used to study the pressure relations in the vascular system of Myxine glutinosa $\mathrm{L}$.

2. The data demonstrate a low arterial pressure level in this species correlating with the existence of a lacunar circulation.

3. The average pressure in the dorsal aorta ranged from $3-8 \mathrm{~mm}$. $\mathrm{Hg}$ with a pulse pressure of around $25 \mathrm{~mm} . \mathrm{H}_{2} \mathrm{O}$. The average pressure drop across the gills, calculated from the average pressures in the heart ventricle and dorsal aorta, was found to be around $4 \mathrm{~mm}$. $\mathrm{Hg}$.

4. The gills have been shown to take active part in the forward propulsion of arterialized blood. This is accomplished by contraction of striated muscular elements in the gills and gill ducts.

5. It is concluded that the circulation in Myxine differs from circulation in vertebrates generally by a partial shifting of the blood-moving power from the systemic heart to the gills and the portal, cardinal and caudal auxiliary hearts.

I am indebted to Professor Dr. Björn Föyn and cand. real. Finn Walvig at the Dröbak Biological Station for providing the material used in this study.

\section{LITERATURE CITED}

Cole, F. J., 1926. A monograph on the general morphology of the Myxinoid fishes, based on a study of Myxine. Part IV. The morphology of the vascular system. Trans. Roy. Soc. Edin., 54: 309-342.

Hofbauer, M., 1937. Anatomischer und Histologischer Bau der Kiemensäcke von Myxine glutinosa. Biologia Generalis., 12: 330-348.

Lyon, E. P., 1926. A study of the circulation, blood pressure and respiration of sharks. J. Gen. Physiol., 8: 279-290.

Marinelli, W., 1956. Myxine glutinosa L. In: Marinelli and Strenger, Vergleichende Anatomie und Morphologie der Wirbeltiere, 2 Wien 1956 (Deuticke).

Мотт, J. C., 1951. Some factors affecting the blood circulation in the common eel (Anguilla anguilla). J. Physiol. (London), 114: 387-398.

Rathke, M. H., 1825. Bemerkungen über den inneren Bau der Pricke oder des Petromyzon fluviatilis Linn. Danzig.

Retzius, A. A., 1822. Vascular system of Myxine. K. Vet. Akad. Handlgr. Stockholm.

Schoenlein, K., And V. Willem, 1894 . Observations sur la circulation du sang chez quelques poissons. Bull. Sci. France et Belg., 26: 442-468.

Scholander, P. F., 1958. Counter current exchange. A principle in Biology. Hvalrådets Skrifter, No. 44. Det Norske Vitenskaps-akademi, Oslo, Norway. 

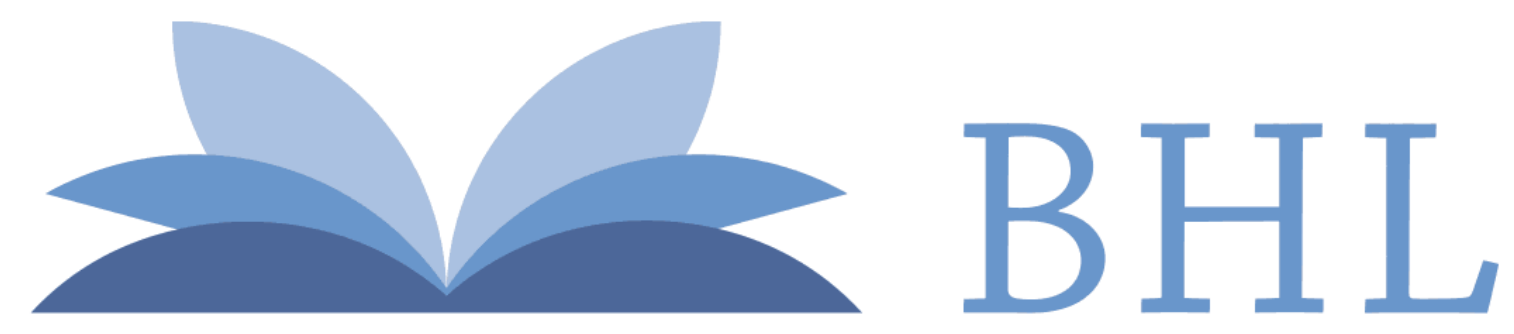

\section{Biodiversity Heritage Library}

Johansen, Kjell. 1960. "Circulation in the hagfish, Myxine glutinosa L." The Biological bulletin 118, 289-295. https://doi.org/10.2307/1539002.

View This Item Online: https://www.biodiversitylibrary.org/item/110976

DOI: https://doi.org/10.2307/1539002

Permalink: $\underline{\text { https://www.biodiversitylibrary.org/partpdf/2136 }}$

\section{Holding Institution}

Smithsonian Libraries

\section{Sponsored by}

Biodiversity Heritage Library

\section{Copyright \& Reuse}

Copyright Status: In copyright. Digitized with the permission of the rights holder.

License: http://creativecommons.org/licenses/by-nc-sa/3.0/

Rights: https://biodiversitylibrary.org/permissions

This document was created from content at the Biodiversity Heritage Library, the world's largest open access digital library for biodiversity literature and archives. Visit BHL at https://www.biodiversitylibrary.org. 